\title{
Pemanfaatan Wellbore Strengthening Agent Selama Pengeboran di Onshore Sumatera Bagian Utara Indonesia
}

\author{
Aly Rasyid \\ Universitas Bhyangkara Jakarta Raya \\ aly.rasyid@dsn.ubharajaya.ac.id
}

\begin{abstract}
Abstrak
Di bagian utara Sumatera onshore Indonesia banyak permasalahan pengeboran ditemukan di daerah tersebut, khususnya di atas pay zone di sumur dengan trajectory dengan kemiringan yang tinggi. Karena pengeboran sumur terakhir di daerah ini adalah era 70', sehingga data yang didapatkan sangat terbatas menjadikan pengeboran di lokasi ini merupakan sebuah tantangan tersendiri, terutama untuk memberikan strategi lumpur pengeboran yang akurat. Untuk mengatasi masalah pengeboran, pemanfaatan agen penguat lubang bor yang diaplikasikan untuk mengurangi masalah lubang bor dan memperkuat sumur dengan filter cake yang efektif. Di bagian Sumatera bagian Utara onshore di Indonesia penggunaan penguat stability luang dijadikan studi kasus. Dalam studi ini, hal yang sangat berpengaruh adalah pemahaman dan dasar-dasar geo-mekanika untuk memberikan penjelasan referensi bagaimana konstruksi well dibentuk termasuk bagaimana filter cake dapat terjadi untuk melindungi stabilitas lubang sumur. Dari hasil dan observasi serta kesimpulan dapat diperoleh dengan menggunakan pengalaman selama pemboran di onshore Sumatera bagian utara, dimana awalnya sangat banyak kendala-kendala operasi selama pemboran, akan tetapi setelah penggunaan agen stabilitas lubang sumur didapatkan kendala-kendala tersebut sangat berkurang.
\end{abstract}

Kata kunci : wellbore strengthening agent, wellbore stability, pemboran, lumpur pemboran

\begin{abstract}
At northern part of Sumatera Indonesian onshore many drilling issues were encountered in the area, in particular the overlying shales above the pay zones in the high deviated trajectory wells. Since the last well drilling in this area was 70' era, so that limited data is another drilling engineering challenge, especially to provide an accurate drilling fluid. To combat the drilling issues, utilization of pre-treated wellbore strengthening agent was applied to reduce well bore issues and strengthen the well with an effective filter cake. In Northern Sumatera Indonesian onshore well in Indonesia was used as a case study. First a brief understanding and fundamentals of geo-mechanics is described in reference to well construction as well as filter cake fundamental to protect the hole stability. Results, observations and conclusions were drawn upon using a case study comparing a well on onshore in Indonesia which had many drilling problems such as stuck pipeldifferential sticking and washouts/hole enlargement issues related to well bore stability, after using the wellbore stability agent, the problems that encountered significantly decrease.
\end{abstract}

Keywords : wellbore strengthening agent, wellbore stability, drilling, drilling mud 


\section{PENDAHULUAN}

Dalam rekayasa geoteknik, fluida pengeboran digunakan untuk membantu pengeboran lubang sumur, diantaranya adalah membantu untuk menahan lubang sumur dari kerontokan karena gaya geoteknik atau disebut dengan geomekanik bumi.

Pengunaan lumpur pemboran selalu diaplikakisan saat pengeboran sumur minyak dan gas alam baik untuk eksplorasi maupun masa pengembangan area blok konsesi migas, juga dalam pengeboran sumur air, dalam bentuk fluida cairan yang lebih sederhana [5][6].

Berbagai jenis lumpur pengeboran, seperti lumpur pengeboran berbasis air (WB), lumpur pengeboran berbasis minyak $(\mathrm{OB})$ dan formulanya digunakan bersama dengan aditif polimer dan clay yang tepat untuk mengebor berbagai formasi minyak dan gas. [1][7][8][9].

\section{METODE PENELITIAN}

Pada study kasus dalam paper ini, penggunaan wellbore strengthening agent pada aktiv system lumpur pemboran, dalam kaitannya untuk memperkuat stabilitas lubang sumur sehingga masalah yang berkaitan dengan ketidakstabilan lubang sumur seperti masalah pembesaran lubang dan diferensial sticking, pipa terjepit bisa dihindari.

Komposisi kimia dan sifat lumpur harus digabungkan untuk menghasilkan lubang sumur yang stabil. Berat lumpur harus berada dalam kisaran yang diperlukan untuk menyeimbangkan kekuatan mekanik. Ketidakstabilan lubang sumur menyebabkan formasi rontok / sloughing, yang dapat menyebabkan kondisi tight hole, bridge/hambatanhambatan selama pemboran maupun saat cabut BHA, maupun pada saat running casing. Jika lubang sumur membesar (washout), maka dinding lubang sumur menjadi lemah dan sulit untuk distabilkan, mengakibatkan masalah seperti kecepatan annular rendah, pembersihan lubang yang buruk, beban cutting formasi yang buruk. Dalam formasi pasir, pembesaran lubang dapat di atasi dengan tindakan mekanis (kecepatan hidrolik \& nozel).

Kerusakan formasi dapat dikurangi oleh sistem hidraulik konservatif. Filter cake yang berkualitas baik yang mengandung bentonit diketahui dapat membatasi pembesaran lubang bor. Pada formasi shale, berat lumpur biasanya cukup untuk mengimbangi formation stress, karena pada shale biasanya lubang sumur lebih stabil. Dengan lumpur berbahan dasar air, perbedaan kimia dapat menyebabkan interaksi antara lumpur pemboran dan shale yang menyebabkan pelunakan formasi. Shale yang memiliki banyak fracture/retakan, kering, rapuh bisa sangat tidak stabil (mengarah ke masalah mekanis). Berbagai inhibitor kimia dapat mengendalikan interaksi lumpur / serpih (kalsium, kalium, garam, polimer, aspal, glikol, dan minyak - terbaik untuk formasi yang peka terhadap air). [2].

Zat wellbore strengthening agent terdiri dari kombinasi bahan lost circulation material (LCM) dengan distribusi ukuran partikel yang dirancang untuk menutup dan menstabilkan setiap jenis formasi batuan. Dalam penelitian ini, berbagai resep wellbore strengthening agent yang telah diterapkan ke dalam system active lumpur pemboran (pretreated) selama pengeboran di onshore bagian utara Sumatera Indonesia

Metode penelitian ini adalah membandingkan hasil pemboran sumur dengan dan tanpa menggunakan pre-treated wellbore strengthening agent serta untuk menemukan resep terbaik agen penguat lubang sumur berdasarkan berbagai resep yang sudah 
diterapkan. Percobaan laboratorium telah dilakukan untuk mendapatkan resep yang sesuai dari agen penguat lubang sumur.

\section{HASIL DAN PEMBAHASAN}

Pada Sumur A 12-1/4" dibor tanpa bahan wellbore strengthening agent. Mulai 121/4" side track Sumur A, Sumur B, Sumur C, dan Sumur dibor dengan menggunakan wellbore strengthening agent.

3 (tiga) perbedaan konsentrasi zat wellbore strengthening agent telah ditambahkan ke sistem fluida pengeboran aktif selama pengeboran di bagian sumur / lubang yang berbeda, sebagai berikut:

1. $5 \mathrm{ppb}$ (2 ppb grafit, $3 \mathrm{ppb}$ kalsium karbonat)

2. $10 \mathrm{ppb}$ (3 ppb grafit, $7 \mathrm{ppb}$ kalsium karbonat)

3. 10 ppb ( 2 ppb grafit, 5 ppb kalsium karbonat, 3 ppb WSA)

Detail pemanfaatan wellbore strengthening agent untuk masing masing bagian lubang ditunjukkan pada Tabel 1.

Adupun hasil dari dampaknya penggunaan wellbore strengthening agent, terhadap kinerja sumur sangat baik. Non Productive Time (NPT) terkait dengan ketidakstabilan lubang sumur berkurang dari $17,1 \%$ menjadi $0,4 \%$ saja (Gambar 1), serta untuk total pengurangan tercatat NPT dari 38\% menjadi $4 \%$ (Gambar 2). Karena itu, kinerja yang baik ini menyebabkan peningkatan seluruh hari rig yang diperlukan untuk pengeboran dan penyelesaian hingga rata-rata 30 hari (Gambar 3).

Tabel 1. Pemanfaatan wellbore strengthening agent

\begin{tabular}{|c|c|c|}
\hline Well & $\begin{array}{l}\text { Hole } \\
\text { Section }\end{array}$ & Pre-treated Wellbore Strengthen ing Agent (WSA) \\
\hline & $17-1 / 2^{\prime \prime}$ & N/A \\
\hline \multirow[t]{4}{*}{ Well A } & $12-1 / 4^{\prime \prime}$ & N/A \\
\hline & $12-1 / 4^{\prime \prime} \mathrm{ST}$ & $5 \mathrm{ppb}$ (2ppb Graphite, 3ppb Calcium Carbonate) \\
\hline & $8-1 / 2^{\prime \prime}$ & $10 \mathrm{ppb}$ (4ppb Graphite, 4ppb Calcium Carbonate, 2ppb WSA) \\
\hline & $17-1 / 2^{\prime \prime}$ & N/A \\
\hline \multirow[t]{4}{*}{ Well B } & $12-1 / 4^{\prime \prime}$ & $10 \mathrm{ppb}$ (7 ppb Calcium Carbonate +3 ppb Graphite) \\
\hline & $8-1 / 2^{\prime \prime}$ & 10 ppb (7 ppb Calcium Carbonate + 3 ppb Graphite) \\
\hline & $8-1 / 2^{\prime \prime} \mathrm{ST}$ & $10 \mathrm{ppb}$ (5 ppb Calcium Carbonate + 2 ppb Graphite +3 ppb WSA) \\
\hline & $17-1 / 2^{\prime \prime}$ & N/A \\
\hline \multirow[t]{3}{*}{ Well C } & $12-1 / 4^{\prime \prime}$ & $10 \mathrm{ppb}(5 \mathrm{ppb}$ Calcium Carbonate $+2 \mathrm{ppb}$ Graphite $+3 \mathrm{ppb}$ WSA) \\
\hline & $8-1 / 2^{\prime \prime}$ & $10 \mathrm{ppb}$ (5 ppb Calcium Carbonate $+2 \mathrm{ppb}$ Graphite $+3 \mathrm{ppb}$ WSA) \\
\hline & $17-1 / 2^{\prime \prime}$ & N/A \\
\hline \multirow[t]{2}{*}{ Well D } & $12-1 / 4^{\prime \prime}$ & $10 \mathrm{ppb}$ (5 ppb Calcium Carbonate $+2 \mathrm{ppb}$ Graphite $+3 \mathrm{ppb}$ WSA) \\
\hline & $8-1 / 2^{\prime \prime}$ & $10 \mathrm{ppb}$ (5 ppb Calcium Carbonate $+2 \mathrm{ppb}$ Graphite $+3 \mathrm{ppb}$ WSA) \\
\hline
\end{tabular}




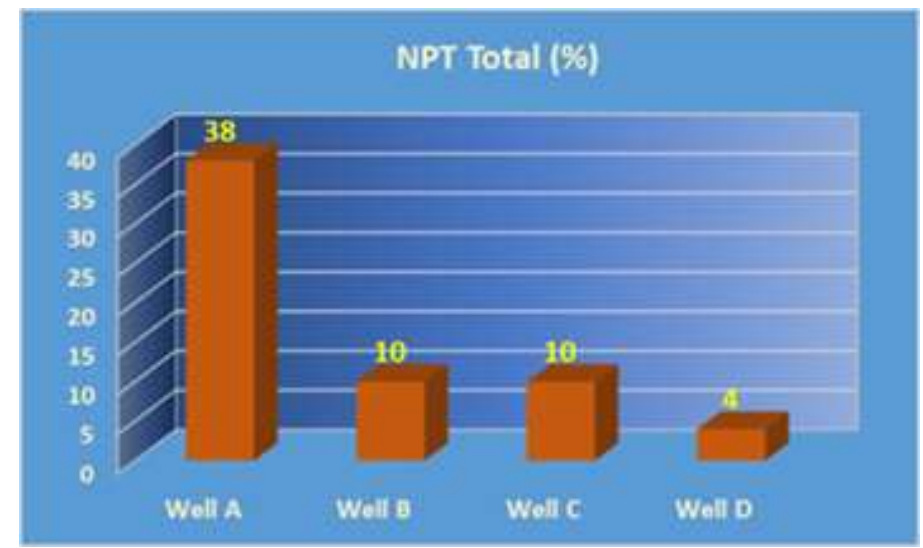

Gambar. 1 Reduksi NPT - Terkait dengan Ketidakstabilan sumur bor (\%)

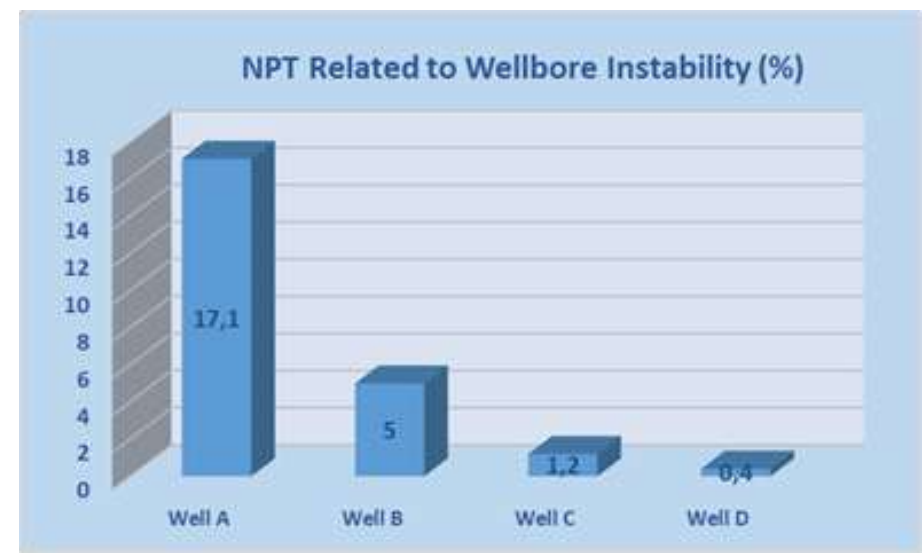

Gambar. 2 Pengurangan Total NPT (\%)

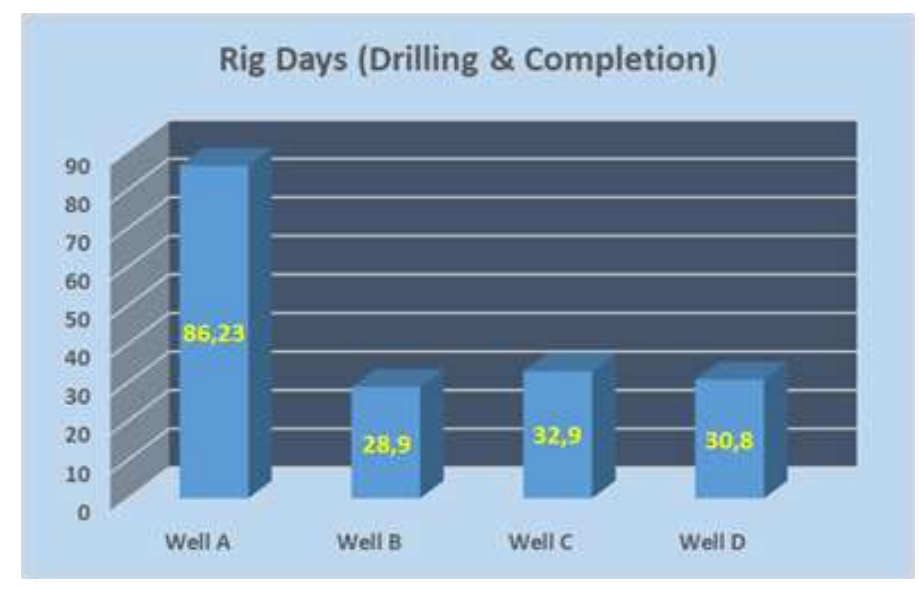

Gambar. 3 Hari Rig 


\section{KESIMPULAN}

Penggunaan pre-treated wellbore strengthening agent memberikan kontribusi yang baik terhadap kinerja sumur pengeboran. Direkomendasikan untuk ditambahkan ke sistem lumpur aktif, tidak hanya dapat memberikan lebih banyak peningkatan stabilitas lubang sumur tetapi juga untuk kinerja pengeboran secara keseluruhan, selama pengeboran, running casing, serta penyemenan.

Sehingga, pada akhirnya dapat mengurangi hari pengeboran, kemudian akan menjadi jauh lebih menguntungkan bagi keseluruhan biaya sumur.

\section{DAFTAR PUSTAKA}

[1] Cheraghian, Goshtasp ; Wu, Qinglin ; Mostofi , Masood ; Li, Mei-Chun; Afrand , Masoud ; S.Sangwai , Jitendra (Oktober 2018). "Pengaruh tanah liat / nano komposit silika baru pada cairan pengeboran berbasis air: Perbaikan dalam sifat reologi dan filtrasi". Koloid dan Permukaan A: Aspek Fisikokimia dan Teknik. 555 : 339350. https://doi.org/10.1016/j.colsurfa.2018.06.072

[2] Buku Pegangan Teknik Perminyakan, Volume II: Pengeboran Mesin . Masyarakat Insinyur Perminyakan . 2007. hlm. 90-95. ISBN 978-1-55563-114-7.

[3] Rabia , Hussain (1986). " Teknik Pengeboran Minyak : Prinsip dan Praktek ", Springer. hlm. 106-111. ISBN 0860106616

[4] Paul Fekete, dan Lopez A. Bruno, University of Calgary; Adewale Dosunmu, dan Samuel Odagme, Shell Aret -Adams; Adewale Sanusi, Universitas Calgary; Ediri Bowe, Universitas Dalhousie, "Pengaruh Stabilitas Sumur Di Waduk yang Pecah Secara Alami", SPE-178267-MS, Konferensi dan Pameran Internasional Tahunan Nigeria diadakan di Lagos, Nigeria, 4 - 6 Agustus 2018

[5] Hernowo Widodo, Lisa Adhani, Elvi Kustiyah, Ilham Santoso, Studi Pengaruh Jenis Katalis, Waktu Reaksi dan Penurunan Bilangan Iodine pada Pembuatan Cocoa Butter Substitute dengan Proses Hidrogenasi Minyak Kelapa. Jurnal Jaring Saintek Volume 1 No. 12019.

[6] Hernowo Widodo, Elsa Maesaroh, Studi Kinetika Reaksi Metil Asetat dari Asam Asetat dan Methanol dengan Variabel Waktu Konsentrasi Katalis, dan Perbandingan Reaktan. Jurnal Ilmiah Widya Volume 3 Nomor 42016.

[7] Meikrismahariyanto, Bungaran Saing, Hernowo Widodo, Concentration Effect of Sodium Carbonate and Sodium Aluminate as Accelerator and $\mathrm{H}_{2} \mathrm{O}$ Mixing against Physical Properties: Flow Ability, Setting Time, and Strength in Low Cement Castable Refractory Product ( Cas Study : PT. Indoporlen ), AIP Conference Prosiding 1877, 090002 ( 2017 ), Langkawi, Malaysia.

[8] Hernowo Widodo , Rehab Laila, Pengaruh Monosodium Glutamat Sebagai Inhibitor Terhadap Kecepatan Korosi dan Karakteristik Mikrostruktur pada Baja AISI 1045 Dengan Media Asam Sitrat dan Kalium Hidroksida. Jurnal Penelitian dan Karya Ilmiah Lemlit Vol 2 No.2 2017.

[9] Hernowo Widodo, Elvi Kustiyah, Niki Wijaya Sari, Andhy Andhy, Mohamad Prastia, Ekstraksi Pektin dari Kulit Pisang Dengan Proses Soletasi. Jurnal Siliwangi Seri Sains dan Teknologi vol 5 No.1 2019 